\title{
Effect of Ammonium Chloride Solution on the Growth of Phosphorus Gypsum Whisker and Its Modification
}

\author{
Shouwei Jian, Mengqi Sun, Guihai He, Zhenzhen Zhi, and Baoguo Ma \\ School of Materials Science and Engineering, Wuhan University of Technology, Wuhan, Hubei 430070, China \\ Correspondence should be addressed to Mengqi Sun; 875864640@qq.com
}

Received 8 May 2016; Revised 11 July 2016; Accepted 3 August 2016

Academic Editor: Victor M. Castaño

Copyright ( 2016 Shouwei Jian et al. This is an open access article distributed under the Creative Commons Attribution License, which permits unrestricted use, distribution, and reproduction in any medium, provided the original work is properly cited.

\begin{abstract}
Phosphogypsum is the by-product of phosphate of fertilizer or phosphate which causes serious environmental pollution. In this work, a series of phosphogypsum whiskers were prepared using phosphogypsum as raw materials and $\mathrm{NH}_{4} \mathrm{Cl}$ as additive through the atmospheric water solution method. The results showed that the ammonium chloride solution has a great influence on phosphogypsum whiskers growth and the solubility. The best whisker aspect ratio of phosphogypsum was preferred in $1 \mathrm{~mol} / \mathrm{L}$ $\mathrm{NH}_{4} \mathrm{Cl}$ solution, in which the solubility achieved $6.434 \mathrm{mg} / \mathrm{mL}$ and the aspect ratio reached 69.29 . Besides, $\mathrm{NH}_{4} \mathrm{Cl}$ was found to have a modified effect on gypsum whiskers' growth and it can be used to get mesh or dendritic whiskers.
\end{abstract}

\section{Introduction}

Phosphogypsum is a solid waste mainly composed of calcium sulfate, $\mathrm{P}_{2} \mathrm{O}_{5}$, and $\mathrm{HF}$, which is the by-product of phosphorus fertilizer or phosphate. Phosphogypsum production is estimated to be around 100-280 megatonnes per year globally and the main producers are in the USA, China, and Africa [1, 2 ]. How to use this special acid waste is a big problem, because the bulk deposition of phosphogypsum not only occupies land but also causes serious environmental pollution.

In China, the primary way to deal with phosphogypsum is to use it in cement and other building materials, while the utilization rate is less than $20 \%$. The reason for this unsatisfying utilization rate is that the phosphogypsum should be dealt with quickly during the production of phosphate and compound fertilizer industry, during which the complex component needs to be purified first (preparation process) and then used for other purposes (production process) [3]. Gypsum whisker preparation is an effective utilization way where the preparation and production can be combined in one process $[4,5]$. At present, there have been some research reports on the use of gypsum in the preparation of whisker. For example, Hamdona and Al Hadad studied the effect of glycine, serine, arginine, and other organic additives [6] and $\mathrm{Cd}^{2+}, \mathrm{Cu}^{2+}, \mathrm{Mg}^{2+}$, and $\mathrm{Fe}^{2+}$ and other metal ions on gypsum crystallization in $\mathrm{CaCl}_{2}-\mathrm{NaSO}_{4}-\mathrm{H}_{2} \mathrm{O}$ system [7]. Luo et al. studied the influence of temperature on the formation of $\mathrm{CaSO} \cdot 0.5 \mathrm{H}_{2} \mathrm{O}$ whiskers and found that, at $130-160^{\circ} \mathrm{C}$, whiskers were produced via the dissolutionprecipitation route [8]. Han et al. investigated the influence of $\mathrm{Na}_{2} \mathrm{HPO}_{4} \cdot 12 \mathrm{H}_{2} \mathrm{O}$ on the hydrothermal formation of hemihydrate calcium sulfate $\left(\mathrm{CaSO}_{4} \cdot 0.5 \mathrm{H}_{2} \mathrm{O}\right)$ whiskers from dihydrate calcium sulfate $\left(\mathrm{CaSO}_{4} \cdot 2 \mathrm{H}_{2} \mathrm{O}\right)$ at $135^{\circ} \mathrm{C}$, and the results showed that the addition of phosphorus accelerated the hydrothermal conversion of $\mathrm{CaSO}_{4} \cdot 2 \mathrm{H}_{2} \mathrm{O}$ to $\mathrm{CaSO}_{4} \cdot 0.5 \mathrm{H}_{2} \mathrm{O}$ via the formation of $\mathrm{Ca}_{3}\left(\mathrm{PO}_{4}\right)_{2}$ and produced $\mathrm{CaSO}_{4} \cdot 0.5 \mathrm{H}_{2} \mathrm{O}$ whiskers with thinner diameters and shorter lengths [9]. Luo et al. used pretreated natural gypsum as raw materials and $\mathrm{MgCl}_{2} \cdot 6 \mathrm{H}_{2} \mathrm{O}$ as additive to study the impact of $\mathrm{MgCl}_{2} \cdot 6 \mathrm{H}_{2} \mathrm{O}$ solution on whisker growth through hydrothermal methods; in the research the aspect ratio of whisker can reach 50-60 [10].

Since gypsum (calcium sulfate) whisker has a small size (diameter between 1 and $100 \mu \mathrm{m}$ ), its specific surface area and contact interface are relatively large. It also has a high surface energy which leads to an easier agglomeration in the preparation and postprocessing process. The effect of agglomeration can make calcium sulfate whisker thicker and 
TABLE 1: Chemical analysis of phosphogypsum.

\begin{tabular}{ccccccccccccc}
\hline $\mathrm{Na}_{2} \mathrm{O}$ & $\mathrm{MgO}$ & $\mathrm{Al}_{2} \mathrm{O}_{3}$ & $\mathrm{SiO}_{2}$ & $\mathrm{P}_{2} \mathrm{O}_{5}$ & $\mathrm{SO}_{3}$ & $\mathrm{~K}_{2} \mathrm{O}$ & $\mathrm{CaO}$ & $\mathrm{TiO}_{2}$ & $\mathrm{Fe}_{2} \mathrm{O}_{3}$ & $\mathrm{SrO}$ & $\mathrm{BaO}$ & $\mathrm{Loss}$ \\
\hline 0.051 & 0.111 & 1.331 & 8.639 & 1.082 & 45.839 & 0.48 & 32.44 & 0.176 & 0.328 & 0.037 & 0.087 & 9.4 \\
\hline
\end{tabular}

larger and can make it lose relevant functional properties. These agglomerated calcium sulfate whiskers with high surface energy cannot adapt to different industries (rubber, plastics, paint, and other industries) demand [11]; therefore, the surface modification of calcium sulfate whisker must be carried out [12-17]. The study by Edinger suggested that the (111) plane of calcium sulfate whisker was made up of calcium ion, which could choose the adsorption of anion. By contrast, the (110) plane was composed of $\mathrm{Ca}^{2+}$ and $\mathrm{SO}_{4}{ }^{2-}$, and it could adsorb both positive and negative ions. Since (110) plane could adsorb anions more easily, it can be seen that the charge performance of the different surface of calcium sulfate whisker would lead to a good performance of modified calcium sulfate whisker [18]. The research by Ling and Demopoulos suggested that the solubility of $\mathrm{CaSO}_{4} \cdot 0.5 \mathrm{H}_{2} \mathrm{O}$ increased initially and then decreased with the concentration of sulfuric acid and the solubility of $\mathrm{CaSO}_{4} \cdot 0.5 \mathrm{H}_{2} \mathrm{O}$ was lower than that without sulfuric acid, which showed that the same ion effect of $\mathrm{SO}_{4}{ }^{2-}$ can effectively reduce the solubility of calcium sulfate [19]. The authors studied the influence of $\mathrm{KCl}$ and $\mathrm{K}_{2} \mathrm{SO}_{4}$ solution on gypsum whiskers and discovered that $\mathrm{K}^{+}$could effectively promote whisker growth in the axial direction, while $\mathrm{SO}_{4}{ }^{2-}$ could inhibit the dissolution of calcium sulfate, so that the phosphogypsum whisker's radial growth was prevented, and its aspect ratio could reach 120 [20].

It is believed that the additives play an important role in crystallization, since they alter the surface properties and change nucleation, growth, and shape of the crystals. There are still some limitations about the basic theory about how to affect the growth of phosphogypsum whisker through the use of ammonium chloride and comparison with other additives for phosphogypsum whisker. For example, the morphology of the whisker prepared in the ammonium chloride solution was found branch-like, which was a newly discovered phenomenon during the author's previous experiment [20]. But it still remains unknown how it was affected in different concentrations. The main objective of this work is to study how the concentration of ammonium chloride affects the whisker growth.

\section{Experiment}

2.1. Experimental Reagents. Industrial waste phosphogypsum was provided by Hubei Chemical Fertilizer Co. Ltd. (China) with grey powder solid, free water content of 23 $25 \%$, and $\mathrm{pH}$ value 2.1. Ammonium chloride of chemical purity, homemade barium acidic chromic acid solution ( $0.05 \mathrm{~mol}$ barium chromate dissolves in $500 \mathrm{~mL} 1 \mathrm{~mol} / \mathrm{L} \mathrm{HCl}$ ), and sodium hydroxide with $1 \mathrm{~mol} / \mathrm{L}$ were also used [21].

Chemical analysis and XRD pattern of phosphogypsum are shown in Table 1 and Figure 1, respectively. The ratio of $\mathrm{P}_{2} \mathrm{O}_{5}$ in phosphogypsum is $1.082 \%$ and it consisted

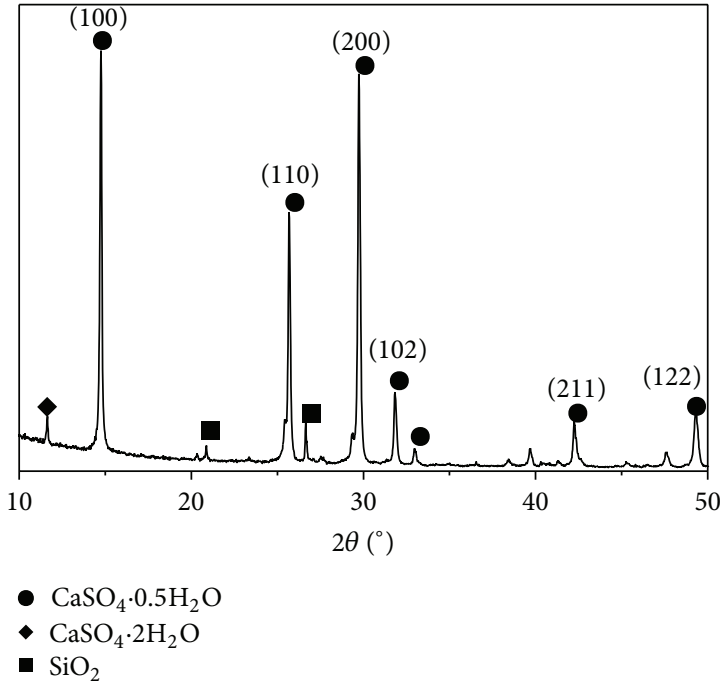

FIGURE 1: XRD pattern of phosphogypsum.

of most irregular $\mathrm{CaSO}_{4} \cdot 0.5 \mathrm{H}_{2} \mathrm{O}$ and a minor amount of $\mathrm{CaSO}_{4} \cdot 2 \mathrm{H}_{2} \mathrm{O}$ and crystalline $\mathrm{SiO}_{2}$.

2.2. Test Procedure. Water treatment of industrial phosphogypsum: $100 \mathrm{~g}$ of industrial waste phosphogypsum and $300 \mathrm{~mL}$ water were placed in a plastic beaker. The glass rod along the cup wall was stirred for $100 \mathrm{r}$ and then kept for $30 \mathrm{~min}$ to make the solution separate to two layers, the suspensions and precipitate, than pouring out the suspensions. This process was repeated for 3 times. This water-washed phosphogypsum was put into an oven to dry at $40^{\circ} \mathrm{C}$, and then it was ground to powder [22].

Determination of solubility of calcium sulfate in different ammonium chloride solution: disposable plastic beaker was used to weigh $10 \mathrm{~g}$ phosphogypsum powder and then $100 \mathrm{~mL}$ various concentrations of ammonium chloride solution $(0.5 \mathrm{~mol} / \mathrm{L}, 1 \mathrm{~mol} / \mathrm{L}, 2 \mathrm{~mol} / \mathrm{L}, 3 \mathrm{~mol} / \mathrm{L}$, and $4 \mathrm{~mol} / \mathrm{L})$ were added. After constant agitation for $60 \mathrm{r}$ (about $2 \mathrm{~min}$ ) with a glass rod, the solution stood still for 1 hour. About $10 \mathrm{~mL}$ supernatant was quickly filtered by $0.22 \mu \mathrm{m}$ syringe suction filter to obtain filtrate $5 \mathrm{~mL}$, and an approximate $2.5 \mathrm{~mL}$ barium acidic chromic acid solution was added to the filtrate. Then distilled water was added to $50 \mathrm{~mL}$ and heated to boiling point for $5 \mathrm{~min}$. Then the flask was removed and cooled for a while, and then a few drops of $1.0 \mathrm{~mol} / \mathrm{L}$ sodium hydroxide were added to make the solution change lemon yellow and 2 more drops were added. After cooling, the solution was transferred to a $50 \mathrm{~mL}$ volumetric flask and diluted to $50 \mathrm{~mL}$. The supernatant was separated (speed $2000 \mathrm{r} / \mathrm{min}$ and time $5 \mathrm{~min}$ ) in TDL-80-2B desktop electric centrifuge after standing for $1 \mathrm{~h}$, taking centrifuge tube supernatant with 


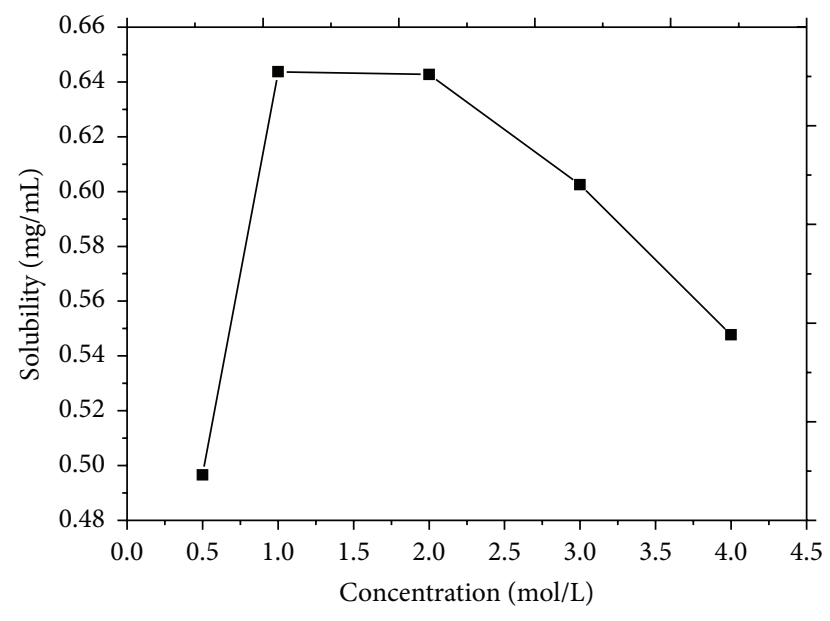

FIGURE 2: The phosphogypsum solubility in $\mathrm{NH}_{4} \mathrm{Cl}$ solution with different concentrations.

$10 \mathrm{~mm}$ cuvette and using UV-5200 UV-Vis spectrophotometer (Shanghai YUANXI Instrument Co., Ltd.) to measure the absorbance at $420 \mathrm{~nm}$ UV wavelengths [21].

2.3. Characterization of Whisker. The light microscopy KH7700 (Questar China Limited) was used to observe the surface morphology and measure the length and width of magnification from 1 to 700 times. The mineral compositions of samples were tested by using a Bruker D8 Advance XRD device with a $\mathrm{Cu} \mathrm{k}_{\alpha} \mathrm{X}$-ray source at $40 \mathrm{kV}$ and $40 \mathrm{~mA}$, with the data collection $2 \theta$ step being $0.02^{\circ}$ and the $2 \theta$ range being $5-70^{\circ}$; the sample needs to be milled and sieved by $200-$ mesh sieve. QUANTA 200 FEG-SEM systems with a $15 \mathrm{kV}$ accelerating voltage and $10 \mathrm{~mm}$ working distance were used to determine the morphology of samples. Attached to this instrument, an X-ray spectrometer system (energy dispersive spectroscopy, EDS) was used to determine chemical compositions after the samples were polished to ensure a smooth surface.

\section{Results and Discussion}

3.1. Phosphogypsum Solubility in Different Ammonium Chloride Solution. The solubility of calcium sulfate is affected by the ammonium chloride solution. The process of preparing gypsum whisker was dissolution-crystallization [23]:

$$
\begin{gathered}
\mathrm{CaSO}_{4} \cdot 0.5 \mathrm{H}_{2} \mathrm{O}(\mathrm{s}) \longleftrightarrow \\
\mathrm{Ca}^{2+}+\mathrm{SO}_{4}^{2-}+0.5 \mathrm{H}_{2} \mathrm{O} \stackrel{1.5 \mathrm{H}_{2} \mathrm{O}}{\longleftrightarrow} \\
\mathrm{CaSO}_{4} \cdot 2 \mathrm{H}_{2} \mathrm{O}(\mathrm{s})
\end{gathered}
$$

Figure 2 is the trend of phosphogypsum solubility in different concentrations of ammonium chloride solution. It showed that the solubility of calcium sulfate rose at first and then declined with the increase of ammonium chloride concentrations. The maximum solubility of calcium sulfate was $6.434 \mathrm{mg} / \mathrm{mL}$ when ammonium chloride concentration

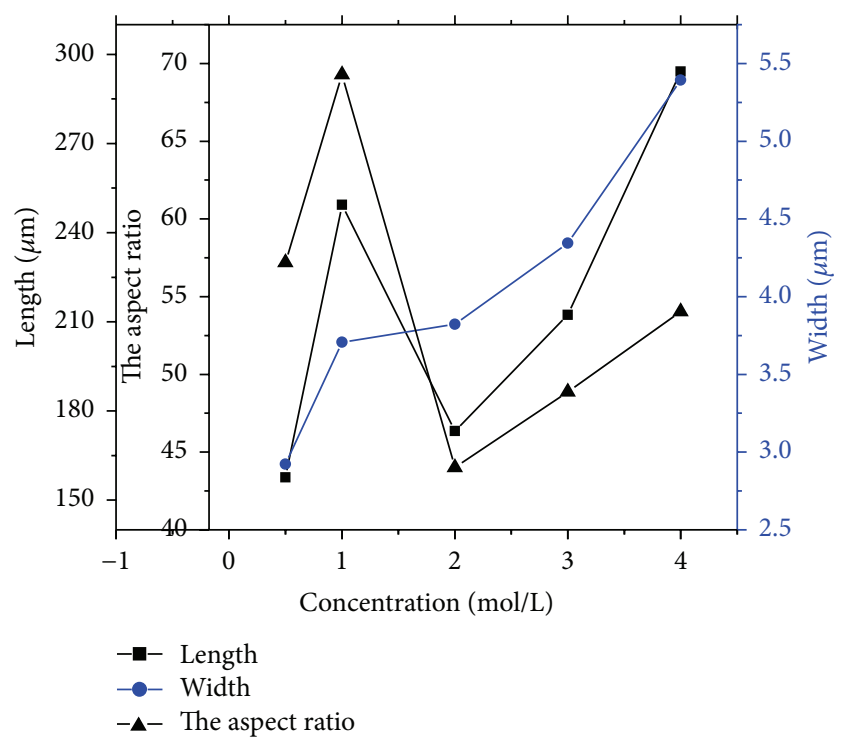

FIGURE 3: The whisker length, width, and draw ratio on different $\mathrm{NH}_{4} \mathrm{Cl}$ solution.

was at $1 \mathrm{~mol} / \mathrm{L}$. The solubility of calcium sulfate was affected by both salt effect and $\mathrm{pH}$ value $[24,25]$. With the increase of the $\mathrm{NH}_{4} \mathrm{Cl}$ concentration, the $\mathrm{pH}$ value of the solution was reduced, which reduced the solubility of calcium sulfate. By contrast, salt effect could increase the solubility of calcium sulfate. As can be seen from the results, at lower concentrations $(<1 \mathrm{~mol} / \mathrm{L})$, the impact of salt on the solubility of calcium sulfate accounted for a major role; and at higher concentrations $(>1 \mathrm{~mol} / \mathrm{L})$, the effect of $\mathrm{pH}$ on the solubility of calcium sulfate was more obvious and the solubility of calcium sulfate decreased with the increase of $\mathrm{NH}_{4} \mathrm{Cl}$ concentration.

3.2. Different Aspect Ratio of Whiskers in Ammonium Chloride Solution. The aspect ratio is an important index of whisker growth, and it has a great effect on its practical application. Figure 3 is whisker growth condition in different concentrations of $\mathrm{NH}_{4} \mathrm{Cl}$ solution. It can be seen that the whisker's average width increased with the increase of ammonium chloride concentrations. The maximum width was $5.398 \mu \mathrm{m}$ at $4 \mathrm{~mol} / \mathrm{L}$, and the length of the whisker varied a lot, with the maximum length $294 \mu \mathrm{m}$ at $4 \mathrm{~mol} / \mathrm{L}$. With the increase of ammonium chloride concentrations, calcium sulfate whisker aspect ratio rose at first, but later it declined and then rose. The maximum aspect ratio of calcium sulfate was 69.292 when ammonium chloride concentration was at $1 \mathrm{~mol} / \mathrm{L}$. The minimum aspect ratio of calcium sulfate was 44.008 when ammonium chloride concentration was at $2 \mathrm{~mol} / \mathrm{L}$. From Figures 1 and 2, the factors of whisker growth were associated not only with phosphogypsum solubility but also with ammonium chloride concentrations.

Figure 4 shows that whiskers grew in different ammonium chloride concentrations, which were $0.5,1.0,2.0$, and $3.0 \mathrm{~mol} / \mathrm{L}$ ammonium chloride solutions, respectively. The whisker growth was needle shaped and it can be seen 

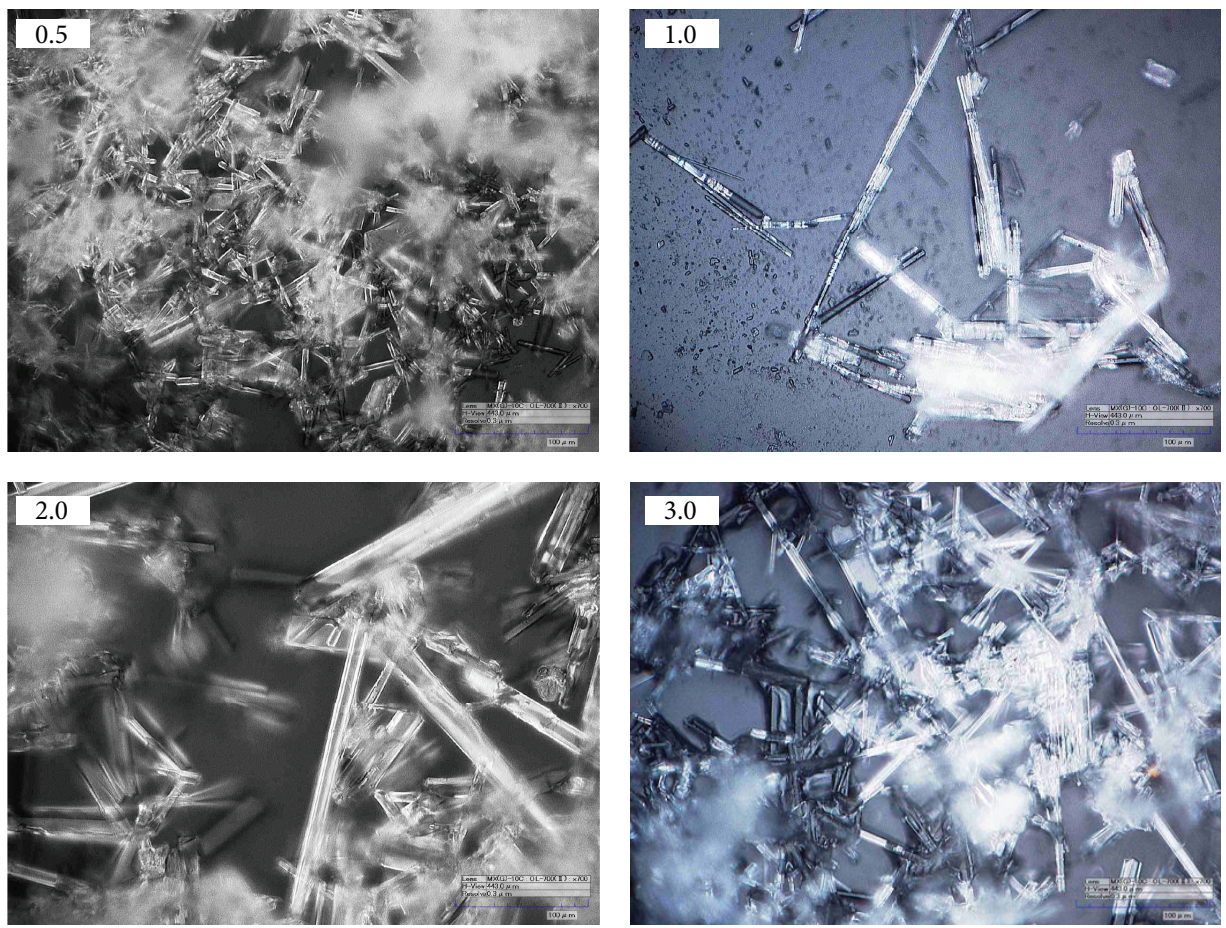

FIGURE 4: Effect of $\mathrm{NH}_{4} \mathrm{Cl}$ solution with different concentrations on whiskers' growth.

that the growth of the whisker in the $1 \mathrm{~mol} / \mathrm{L}$ ammonium chloride solution was noticeable with length $355 \mu \mathrm{m}$. The aspect ratio of both whiskers reached about 55 and the other two whiskers' aspect ratio reached about 45 . What is more, the samples showed different status under different environmental conditions. Under wet conditions, whiskers were shown in Figure 4; in contrast, with the loss of water, the samples gradually dried (Figure 5) and the whiskers became cross-linking, forming dendrites.

Figure 5 is whisker pictures for experiment observed under a microscope, with the whiskers sample reticular or dendritic distributed. In (a) of Figure 5, the whisker shown rendered mesh distribution and the other three were like the branches divergent distribution. With observation by optical microscope, the initial morphosis of samples is short rod and not cross-linked to each other. With the gradual drying of the sample, the smaller and finer whiskers will gradually flow, presented in Figure 5. The morphology of samples is mesh and twigs whisker-like. It will be discussed in detail in Section 3.4.

3.3. XRD Phase Analysis of Whiskers. Figure 6 showed the XRD analysis of phosphogypsum whiskers sample in $\mathrm{NH}_{4} \mathrm{Cl}$ solution with different concentrations. The figure marked the peak which was the $\mathrm{CaSO}_{4} \cdot 2 \mathrm{H}_{2} \mathrm{O}$ characteristic diffraction peaks and the main component of several analytical samples was $\mathrm{CaSO}_{4} \cdot 2 \mathrm{H}_{2} \mathrm{O}$. The stronger intensity characteristic diffraction peaks represented that whisker grew more fully and with better crystallization. The intensity of the characteristic diffraction peaks of samples in different concentrations of $\mathrm{CaSO}_{4} \cdot 2 \mathrm{H}_{2} \mathrm{O}$ was almost the same, with no significant differences.
TABLE 2: Crystallinity of whiskers sample.

\begin{tabular}{lccccc}
\hline Concentration (mol/L) & 0.5 & 1 & 2 & 3 & 4 \\
\hline Crystallinity (\%) & 88.18 & 86.15 & 86.52 & 85.77 & 85.69 \\
\hline
\end{tabular}

Jade 6 was used to calculate the crystallization of whisker in different concentration of $\mathrm{NH}_{4} \mathrm{Cl}$ solutions. As shown in Table 2, the degree of crystallinity of $\mathrm{CaSO}_{4} \cdot 2 \mathrm{H}_{2} \mathrm{O}$ did not change much with the increase of concentration: in the $0.5 \mathrm{~mol} / \mathrm{L} \mathrm{NH}_{4} \mathrm{Cl}$ solution, the value of crystallization degree was $88.18 \%$ and in $4 \mathrm{~mol} / \mathrm{L}$ the crystallization degree value was $85.69 \%$.

3.4. Modification of Calcium Sulfate Whisker by Ammonium Chloride Solution. Because dendritic whisker was observed after the sample was dried on glass, the reason was considered to be the $\mathrm{NH}_{4} \mathrm{Cl}$ solution making calcium sulfate whisker cross-linked to produce dendritic crystals. In the same area, the state of the whisker was observed with time. The results were shown in Figure 7.

As can be seen from Figure 7, the sample picture (a) was randomly distributed in the initial observation. With the gradual drying of the sample, several large branches appeared, as well as some fine short rods of small particles in picture (b) and (c). Then the main part of the sample branches gradually got thicken and the part had been elongated in the picture (d). Due to the drying sample, the precipitation of ammonium chloride would act as a bridge to connect with main part of the sample. This confirmed that the ammonium chloride had a certain role in modification on the whisker. 


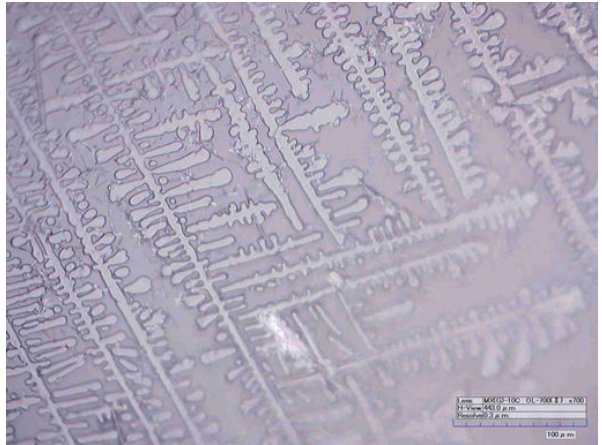

(a)

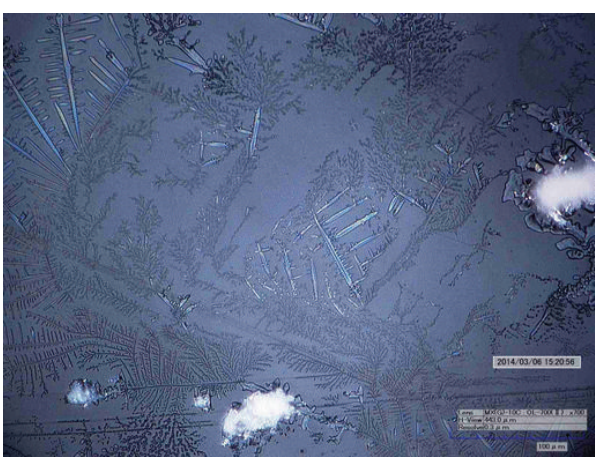

(c)

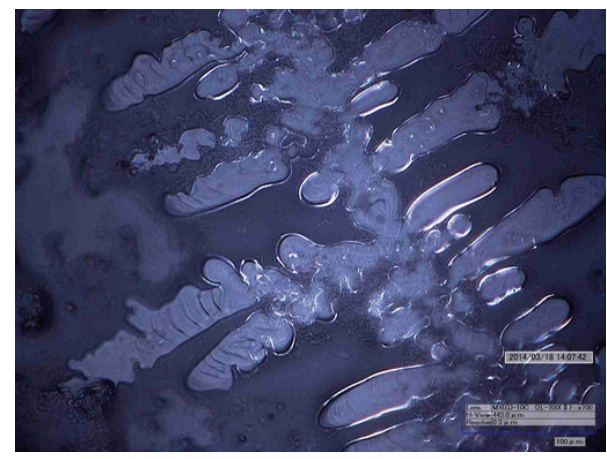

(b)

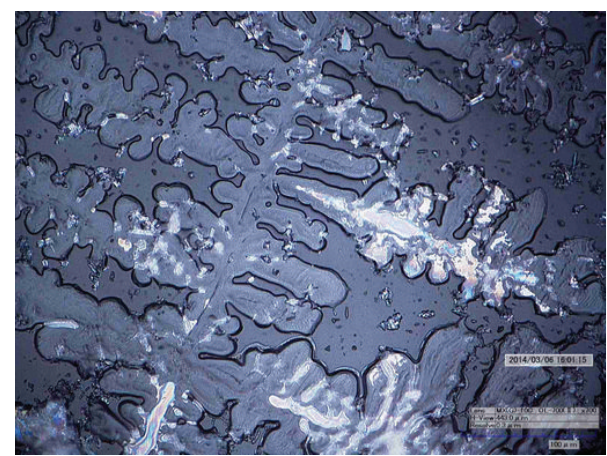

(d)

FIgURE 5: The mesh whisker observed in $\mathrm{NH}_{4} \mathrm{Cl}$ solution.
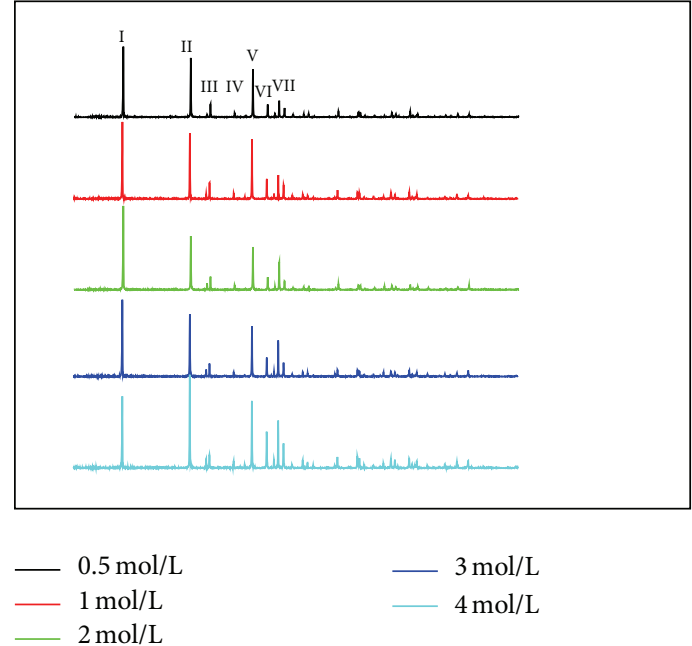

FIGURE 6: The XRD analysis of gypsum whisker in $\mathrm{NH}_{4} \mathrm{Cl}$ solutions with different concentrations.

The gypsum whisker which grew in different salt solution (Figure 8) was observed after $\mathrm{NH}_{4} \mathrm{Cl}$ solution was added. The whisker of Figure 8(a) grew in $\mathrm{KCl}$ solution. The addition of ammonium chloride solution sample into a dendritic whisker made some fine small particles connected to the whisker, resulting in whiskers obtaining elongation. The whisker of Figure 8(b) grew in $\left(\mathrm{NH}_{4}\right)_{2} \mathrm{SO}_{4}$ solution. As the $\left(\mathrm{NH}_{4}\right)_{2} \mathrm{SO}_{4}$ solution was not satisfactory, most of which was small, short
TABLE 3: The result of EDS.

\begin{tabular}{lccc}
\hline Element & \multicolumn{3}{c}{ Atomic percentage } \\
& 1 & 2 & 3 \\
\hline $\mathrm{Cl}$ & 59.80 & 64.12 & 1.2 \\
$\mathrm{Ca}$ & $/$ & $/$ & 14.09 \\
$\mathrm{~S}$ & 0.19 & 0.24 & 12.94 \\
$\mathrm{O}$ & $/$ & $/$ & 65.95 \\
$\mathrm{~N}$ & 40.01 & 35.64 & 5.82 \\
\hline
\end{tabular}

rods, while in Figure 8(b) the dendritic or mesh whisker can be observed. It showed that ammonium chloride had a certain effect on the modification and growth of the whisker.

To verify the effect of ammonium chloride on whisker modification, the sample's SEM and EDS (Figure 9) were observed and detected. Figure 9 showed that the dendritic whiskers were connected by the ammonium chloride. Three points were tested in EDS with the data of the results shown in Table 3. Point 1 and point 2 were located in the crystal branches, while point 3 was located on the main stem of the crystal. The data of the table showed that the main elements of point 1 and point 2 were $\mathrm{Cl}$, while the main atoms of point 3 were $\mathrm{Ca}, \mathrm{S}$, and $\mathrm{O}(\mathrm{Ca}: \mathrm{S}: \mathrm{O} \approx 1: 1: 6)$, which suggested that the main components could be $\mathrm{CaSO}_{4} \cdot 2 \mathrm{H}_{2} \mathrm{O}$ at point 3 and $\mathrm{NH}_{4} \mathrm{Cl}$ at points 1 and 2. Therefore, it can be concluded that the main structure of dendritic crystal was $\mathrm{CaSO}_{4} \cdot 2 \mathrm{H}_{2} \mathrm{O}$, and the branches were $\mathrm{NH}_{4} \mathrm{Cl}$. According to the research [26-28], the mechanism of the formation and the growth 


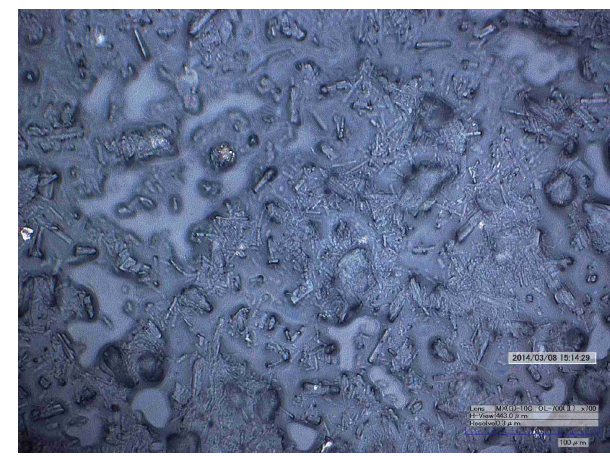

(a)

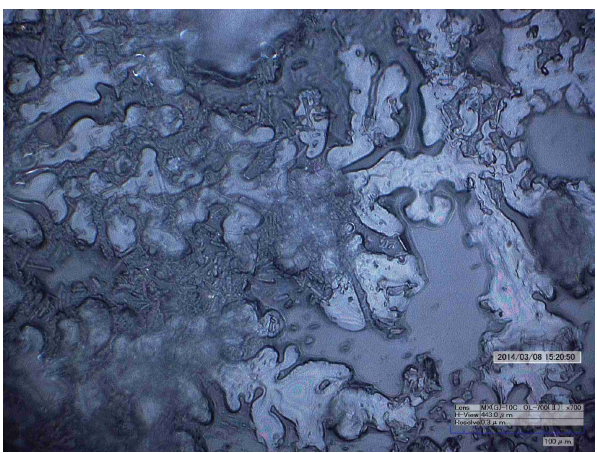

(c)

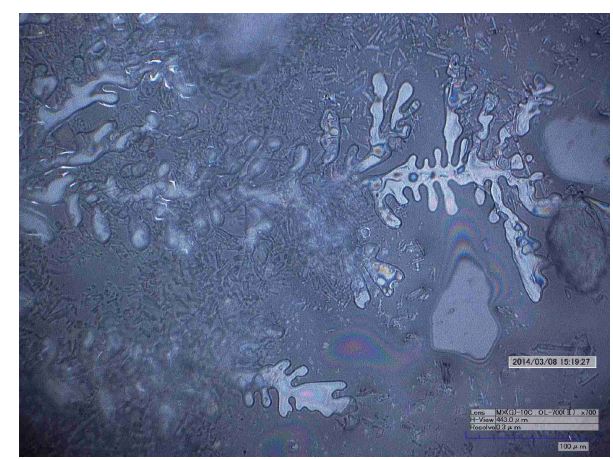

(b)

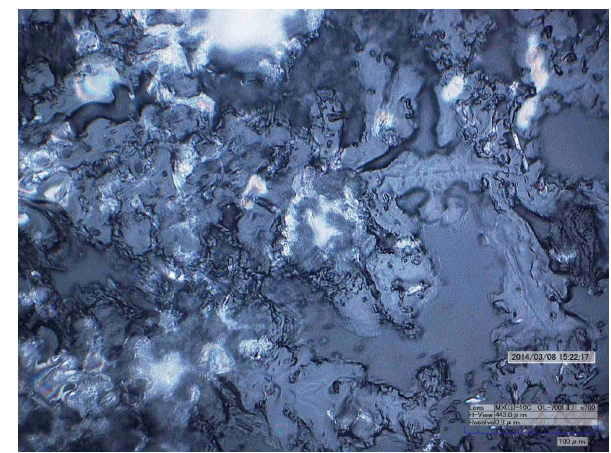

(d)

FIGURE 7: Same area observed whisker morphology pictures with time.
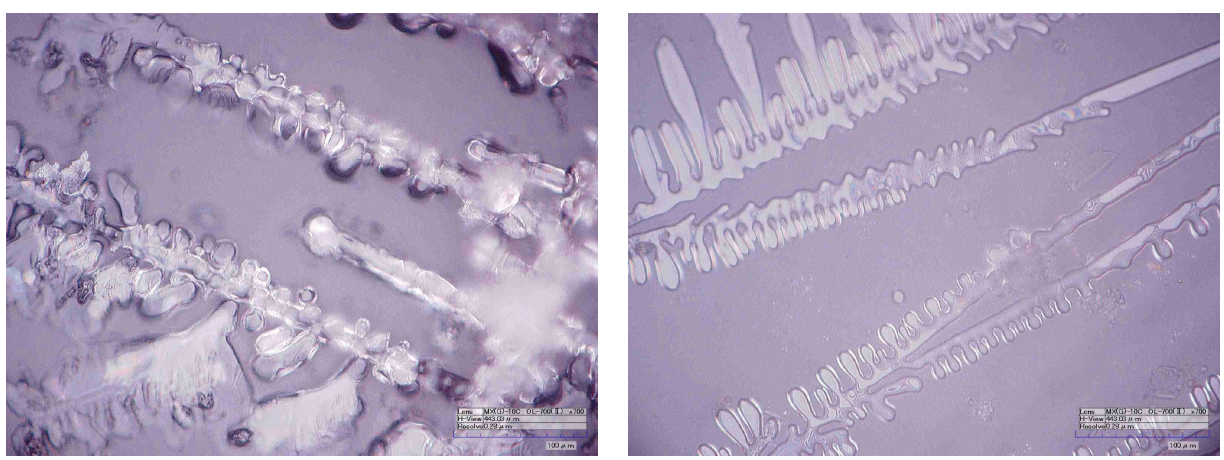

(a)
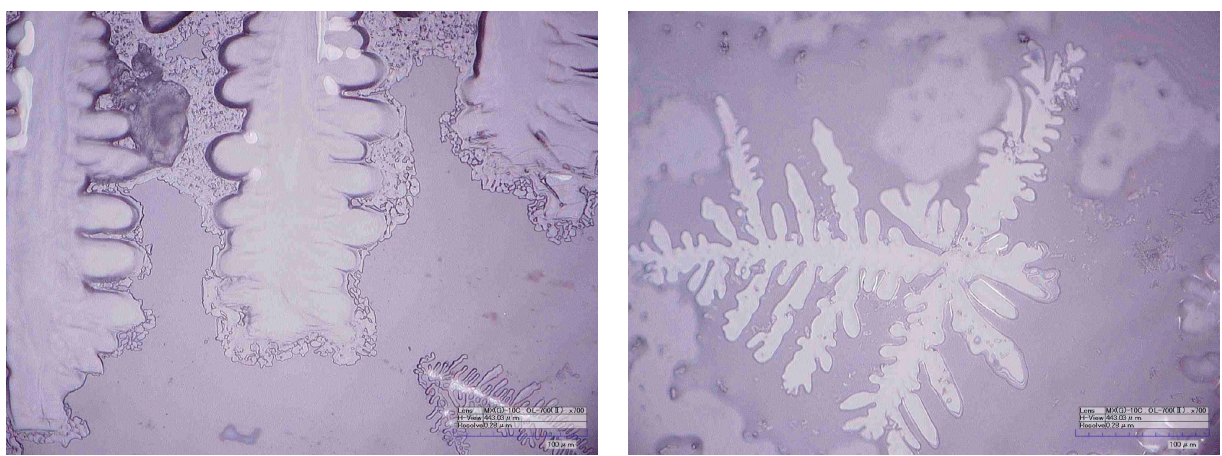

(b)

FIGURE 8: The image gypsum whisker growth in different salt solution was observed after $\mathrm{NH}_{4} \mathrm{Cl}$ solution was added. 

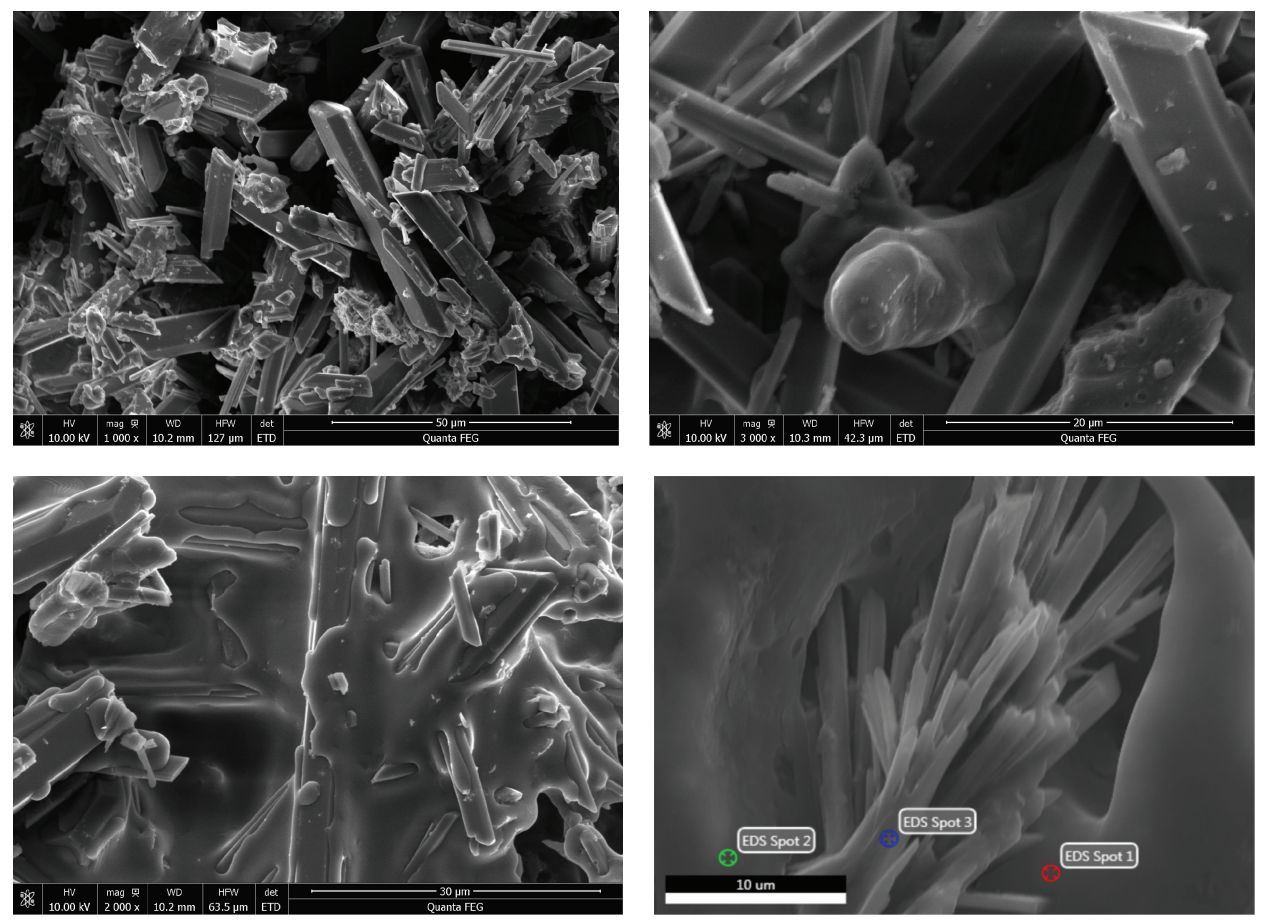

FIGURE 9: The sample picture under electron microscope.

of seaweed-like dendrite of $\mathrm{NH}_{4} \mathrm{Cl}$ was a crystal surface of a "mother" crystal nucleation and growth of second "sub" crystal. In this paper, the main component of the crystal was $\mathrm{CaSO}_{4} \cdot 2 \mathrm{H}_{2} \mathrm{O}$, so it must be the "mother" crystal. The $\mathrm{NH}_{4} \mathrm{Cl}$ crystal grew on one crystal surface of $\mathrm{CaSO}_{4} \cdot 2 \mathrm{H}_{2} \mathrm{O}$ and gradually became "seaweed-like dendrite" and because the morphology of $\mathrm{CaSO}_{4} \cdot 2 \mathrm{H}_{2} \mathrm{O}$ was whisker, the "seaweedlike dendrite" was dendrite.

\section{Conclusions}

The effects of different concentrations of $\mathrm{NH}_{4} \mathrm{Cl}$ on the growth of phosphogypsum whiskers were discussed in this paper. The results showed that the phosphorus gypsum in different concentrations of $\mathrm{NH}_{4} \mathrm{Cl}$ can grow different length to diameter ratio dendritic crystal, and the XRD results showed that the crystals were mainly composed of $\mathrm{NH}_{4} \mathrm{Cl}$ and $\mathrm{CaSO}_{4} \cdot 2 \mathrm{H}_{2} \mathrm{O}$. SEM and EDS results confirmed that dendrite structure was that $\mathrm{CaSO}_{4} \cdot 2 \mathrm{H}_{2} \mathrm{O}$ acted as the skeleton and $\mathrm{NH}_{4} \mathrm{Cl}$ as connection points. Because the structure of $\mathrm{CaSO}_{4} \cdot 2 \mathrm{H}_{2} \mathrm{O}$ crystal is complete, which can be easily separated from $\mathrm{NH}_{4} \mathrm{Cl}$, the phenomenon can lay the foundation for the purification of $\mathrm{CaSO}_{4} \cdot 2 \mathrm{H}_{2} \mathrm{O}$ in phosphogypsum.

\section{Competing Interests}

The authors declare that they have no competing interests.

\section{Acknowledgments}

This paper is supported by Science and Technology Support Program of Hubei Province, 2015BCA303, and the relevant testing technology was supported by the material research and test center of Wuhan University of Technology; the part of the translation was supported by the LIU Min of the UCL.

\section{References}

[1] C. Papastefanou, S. Stoulos, A. Ioannidou, and M. Manolopoulou, "The application of phosphogypsum in agriculture and the radiological impact," Journal of Environmental Radioactivity, vol. 89, no. 2, pp. 188-198, 2006.

[2] A. Ghosh, "Compaction characteristics and bearing ratio of pond ash stabilized with lime and phosphogypsum," Journal of Materials in Civil Engineering, vol. 22, no. 4, pp. 343-351, 2010.

[3] R. Liao and X. Xu, "Situation and prospects of China's the phosphogypsum resources applications," Sulphuric Acid lndustry, vol. 3, pp. 1-7, 2012.

[4] J. Qin, "Analysis on comprehensive utilization of phosphogypsum," China Resources Comprehensive Utilization, vol. 28, no. 3, pp. 23-25, 2010.

[5] Y. Bulei, "Comprehensive utilization of phosphogypsum," Guizhou Chemical Industry, vol. 1, article 012, 2010.

[6] S. K. Hamdona and O. A. Al Hadad, "Influence of additives on the precipitation of gypsum in sodium chloride solutions," Desalination, vol. 228, no. 1-3, pp. 277-286, 2008.

[7] S. K. Hamdona and U. A. Al Hadad, "Crystallization of calcium sulfate dihydrate in the presence of some metal ions," Journal of Crystal Growth, vol. 299, no. 1, pp. 146-151, 2007.

[8] K. Luo, C. Li, L. Xiang, H. Li, and P. Ning, "Influence of temperature and solution composition on the formation of calcium sulfates," Particuology, vol. 8, no. 3, pp. 240-244, 2010.

[9] Q. Han, K. Luo, H. Li, and L. Xiang, "Influence of disodium hydrogen phosphate dodecahydrate on hydrothermal formation of hemihydrate calcium sulfate whiskers," Particuology, vol. 17, pp. 131-135, 2014. 
[10] K. B. Luo, H. P. Li, and Y. X. Tan, "Study on the preparation of calcium sulfate whisker by hydrothermal method," Advanced Materials Research, vol. 602-604, pp. 1369-1372, 2013.

[11] J. Ren, J. Shen, and S. Lu, Particle Dispersion Science and Technology, Chemical Industry Press, Beijing, China, 2005.

[12] W.-Z. Yin, X.-L. Wang, Y.-X. Han, and Z.-T. Yuan, "Surface modification of calcium sulphate whiskers," Journal of Northeastern University, vol. 28, no. 4, pp. 580-583, 2007.

[13] X. Hu and M. Yu, "Study of calcium sulphate whiskers modified bismaleimide resin by friction and wear properties," Acta Polymerica Sinica, no. 5, pp. 686-691, 2006.

[14] D. Wang, J. Yang, and P. Huang, "Adhesive properties of calcium sulfate whisker-modified polyurethane-epoxy resins," Acta Materiae Compositae Sinica, vol. 25, no. 4, pp. 1-6, 2008.

[15] Z. Wang, Y. Han, Z. Yuan et al., "Calcium sulfate whiskers preparation and its application," Mining and Metallurgy, vol. 2, article 009, 2005.

[16] L. Li, Y. Han, and S. Tao, "Research on surface modification of calcium carbonate whiskers," Industrial Minerals \& Processing, vol. 44, no. 5, pp. 4-8, 2008.

[17] L. Wang, C.-Y. Zhuang, X.-X. Zhu, C. Liu, D.-Q. Meng, and J. Fang, "Research on the modification and dissolution-inhibiting of calcium sulfate whisker," Journal of Functional Materials, vol. 43, no. 14, pp. 1833-1836, 2012.

[18] S. E. Edinger, "An investigation of the factors which affect the size and growth rates of the habit faces of gypsum," Journal of Crystal Growth, vol. 18, no. 3, pp. 217-224, 1973.

[19] Y. B. Ling and G. P. Demopoulos, "Solubility of calcium sulfate hydrates in (0 to 3.5$) \mathrm{mol} \cdot \mathrm{kg}^{-1}$ sulfuric acid solutions at $100^{\circ} \mathrm{C}$," Journal of Chemical and Engineering Data, vol. 49, no. 5, pp. 1263-1268, 2004.

[20] S. Jian, M. Sun, Z. Zhi et al., "The impact of $\mathrm{K}_{2} \mathrm{SO}_{4}$ solution on phosphogypsum whisker growth and crystallization process," Functional Materials, vol. 24, pp. 24043-24047, 2015.

[21] B.-G. Ma, W. Hou, X.-H. Ru et al., "Spectrophotometric method for measuring solubility of phosphorus gypsum," Journal of Wuhan University of Technology, vol. 34, no. 4, pp. 15-19, 2012.

[22] M. A. Lin-Zhuan, N. Ping, Y. Yue-Hong et al., "Review on the technology of phosphogypsum pretreatment," Phosphate \& Compound Fertilizer, no. 3, pp. 62-63, 2007.

[23] E. A. Abdel-Aal, M. M. Rashad, and H. El-Shall, "Crystallization of calcium sulfate dihydrate at different supersaturation ratios and different free sulfate concentrations," Crystal Research and Technology, vol. 39, no. 4, pp. 313-321, 2004.

[24] W.-H. Xie, W.-Y. Shiu, and D. Mackay, "A review of the effect of salts on the solubility of organic compounds in seawater," Marine Environmental Research, vol. 44, no. 4, pp. 429-444, 1997.

[25] A. T. M. Serajuddin, "Salt formation to improve drug solubility," Advanced Drug Delivery Reviews, vol. 59, no. 7, pp. 603-616, 2007.

[26] S. Zhao, Z. Qiu, M. Yang, J. Meng, and M. Fang, "Crystallographic symmetry effect on the nucleation in non-equilibrium aggregation pattern," Physica A: Statistical Mechanics and its Applications, vol. 387, no. 22, pp. 5355-5361, 2008.

[27] X.-Y. Liu and C. S. Strom, "Self-epitaxial nucleation origin of fractal aggregation," Journal of Chemical Physics, vol. 113, no. 10, pp. 4408-4411, 2000.

[28] X. Y. Liu, "A new kinetic model for three-dimensional heterogeneous nucleation," Journal of Chemical Physics, vol. 111, no. 4, pp. 1628-1635, 1999. 

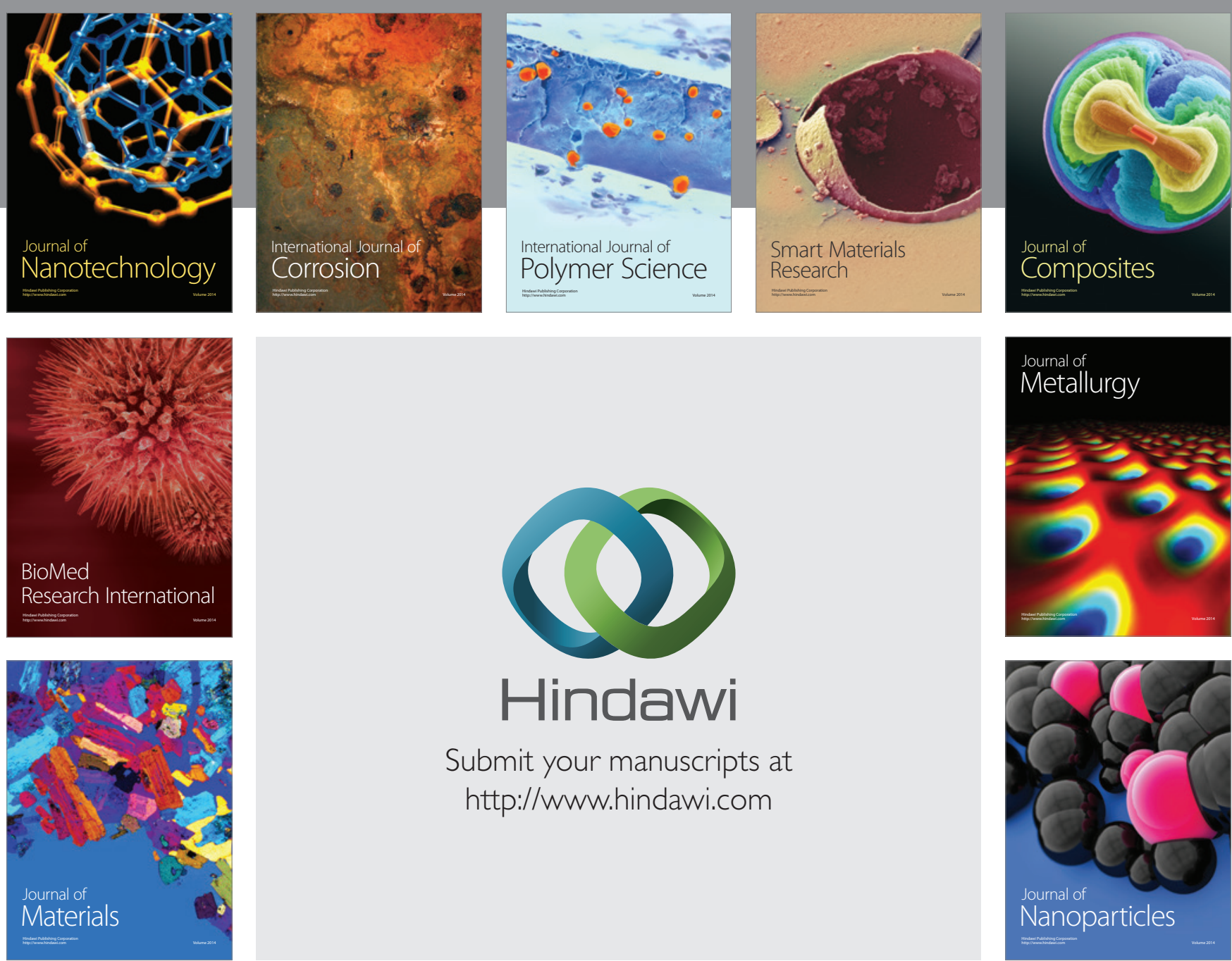

\section{Hindawi}

Submit your manuscripts at

http://www.hindawi.com

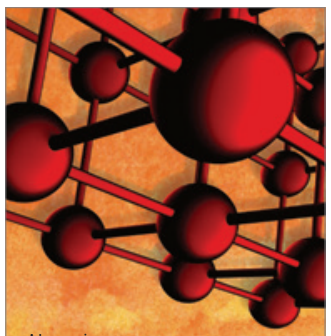

Materials Science and Engineering
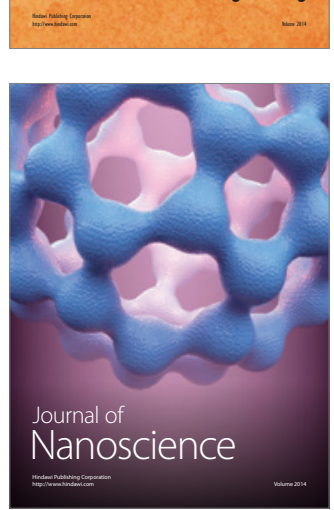
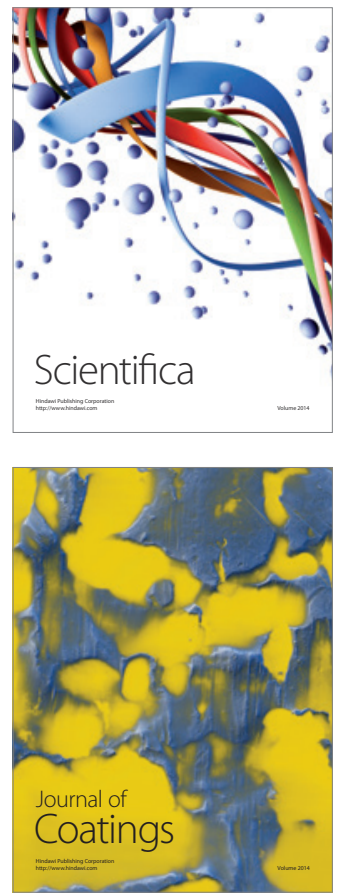
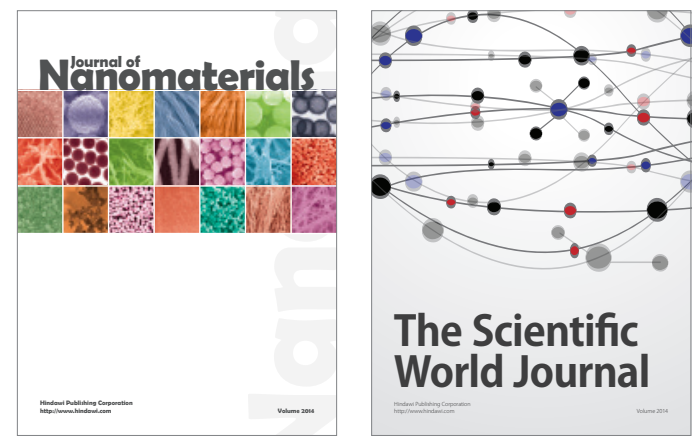

The Scientific World Journal
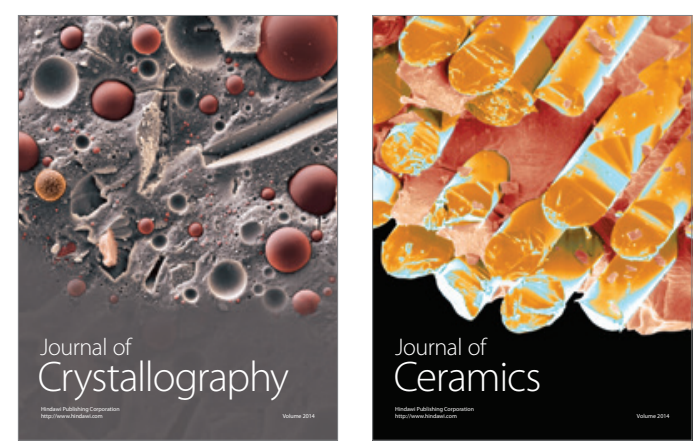
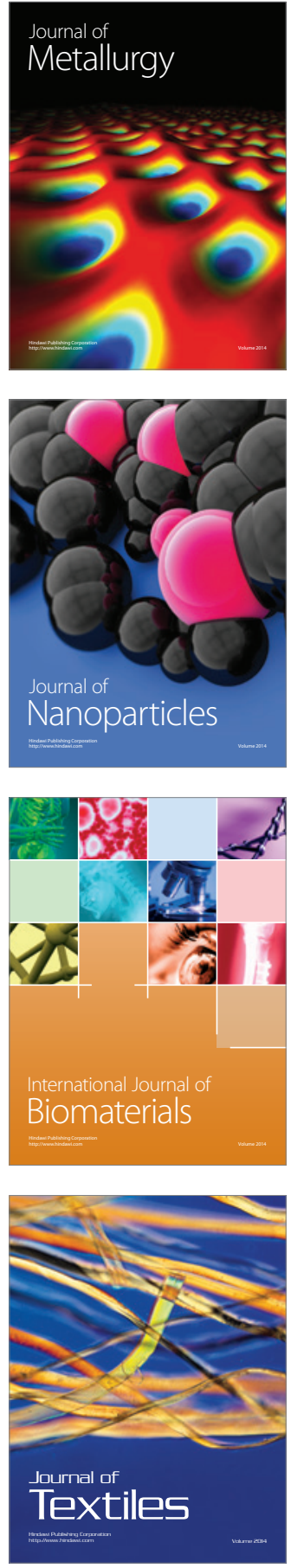